\title{
Screen Dependency Disorders in children under two years of age: A Parent Report Measure
}

Anjali $^{1}$, Ipsa Mohapatra ${ }^{2}$, Ankita Banerjee ${ }^{3}$

${ }^{1}$ Undergraduate Student, Kalinga Institute of Medical Sciences, KIIT University, Bhubaneswar, Odisha- 751024; ${ }^{2}$ Associate Professor, Department of Community Medicine, Kalinga Institute of Medical Sciences, KIIT University, Bhubaneswar, Odisha751024; ${ }^{3}$ Postgraduate Student, Department of Community Medicine, Kalinga Institute of Medical Sciences, KIIT University, Bhubaneswar, Odisha- 751024

\begin{tabular}{|c|c|c|c|c|c|c|c|c|}
\hline Abstract & Introduction & Methodology & Results & Conclusion & References & Citation & \multicolumn{2}{|c|}{ Tables / Figures } \\
\hline \multicolumn{9}{|c|}{ Corresponding Author } \\
\hline \multicolumn{8}{|c|}{$\begin{array}{l}\text { Dr Ipsa Mohapatra, Department of Community Medicine, Kalinga Institute of Medical Sciences, KIIT } \\
\text { University, Bhubaneswar, Odisha- 751024 } \\
\text { E Mail ID: } \underline{\text { dr ipsa@yahoo.co.in }}\end{array}$} & 回语回 \\
\hline
\end{tabular}

\section{Citation}

Anjali, Mohapatra I, Banerjee A. Screen Dependency Disorders in children under two years of age: A Parent Report Measure. Indian J Comm Health. 2020;32(2):427-431.

Source of Funding: Nil Conflict of Interest: None declared

\section{Article Cycle}

\begin{tabular}{|c|}
\hline Received: 15/05/2020; Revision: 25/05/2020; Accepted: 15/06/2020; Published:30/06/2020 \\
\hline This work is licensed under a Creative Commons Attribution 4.0 International License. \\
\hline
\end{tabular}

\section{Abstract}

Screen dependency disorder is on a rising trend and being less researched, the study tried to find out the prevalence and pattern of screen viewing (SV) among children less than two-years of age. Data was collected through in-person interviews from their mothers. Increasing child-age and type of family were significantly associated with higher prevalence of SV. Smart phones had similar usage rates as TVs. Parental knowledge and practices were found to influence the SV and screen-time in children. Modifiable factors like parental knowledge on SV, parental SV practices can help in designing health promotion strategies and recommendations on SV.

\section{Keywords}

Dependency, Screen-Viewing, Screen-Time, Child, Parental

\section{Introduction}

The rising trend of excessive use of screens and digital media, a growing challenge for child neurology, leads to exposure to blue lights, which has an impact on the child's brain and leads to a disorder called Screen Dependency Disorder (SDD) $(1,2,3)$. Screen time (ST) not only has an impact on the child's behavior and attention, but leads to sleep disturbances and adversely impacts brain development (4). Studies have reported, televisions in bedrooms (5) being associated with higher screen viewing (SV); SV in infancy, with around 88.2 percent allowed daily ST, with television and mobile devices being the most commonly used (6) and with most children living in homes where there are no parental rules regarding ST, parental television viewing time is seen to be more closely associated with children's viewing time (7).

\section{Aims \& Objectives}

Screen dependency being less researched this study was done with the objectives:
1. To find out the prevalence of total and device-specific screen viewing,

2. To study the pattern of screen viewing and its determinants

\section{Material \& Methods}

Study Type: Cross- Sectional Study

Study Population: were the mothers of children aged two years and below who came for the routine clinic visits during May- June 2019.

Study Area: was a well baby clinic of a Medical College situated in Bhubaneswar, Odisha

Study duration: April - October 2019 with data collection period of two months (May- June 2019)

Sample size: During the two month period, May -June 2019, a total of 152 children less than two years visited the well baby clinic attached to the immunization centre, of the tertiary care hospital; of whom 13 had a repeat visit were hence excluded. 139 satisfied the inclusion criteria, 105 (75.54\%) consented to be a part of the study, making 105 the final sample size. 
Inclusion criteria: Mothers with children in the age group of less than two years, who were residents of the selected area for more than one year and those who gave an informed written consent.

Exclusion criteria: Mothers who were not staying with their children, who were mentally incapacitated and were not in a position to give reliable information and who had already participated in the study earlier.

Sampling technique: convenience sampling

Study instrument: was a semi-structured, researchermade, interviewer-administered questionnaire containing both closed and open ended questions on socio-demographic, parental and home environment of the child, device-specific information on SV of the child, parental knowledge of SV recommendations, home digital technology survey [mothers were asked questions about the types of digital devices the family had at home, how much time the child spent using these devices, how easy were the devices for the child to use (1: very difficult to 5: very easy)] and parental use of technology at home and beliefs

Ethical Approval: The study protocol was approved by ethics committee [letter no. KIIT/KIMS/IEC/25/2019 dated 30.4.2019]. After contacting the eligible mothers, briefing them about the study, consent was taken and a face to face interview done. At the end they were briefed on recommendations of SV.

Data Analysis: All questionnaires were checked for completeness at the end of each session and day of data collection. Data was entered into Microsoft excel 2007 spreadsheet and analysed using Epi info software [LANGUAGE en-US version 7.2.3.1]. For categorical variables, frequencies and percentages were used. For continuous variables mean \& standard deviation and median and inter-quartile range [IQR] were used. To find out the association between categorical variables the chisquare or fisher exact test were used where appropriate. A level of 0.05 was considered as statistically significant.

\section{Results}

Child and parental socio-demographic characteristics of the eligible and consenting 105 mother-child pair visiting the well baby clinic during the study period are presented in (Table 1). The median age of the children was 9 months. The prevalence of daily SV was $41.90 \%$ (Table 2). $14(13.33 \%)$ reported as not having any digital device at home. $86.67 \%$ of the families reported to have atleast one digital device at home; the child spending an average of $1.28 \pm 1.93$ hours per day, [range zero to nine hours]. The families reported an average of three hours/day of TV use (including background television) at home. The fathers reported an average of 1-2hours/day (range 0-4 hrs) of TV viewing, while the mothers 1-2 hours/day (range 0.5-6 hrs). Most common being television (81.90\%), followed by smart phones (60.96\%) and laptop (13.33\%). iPads $(2.86 \%)$ and desktops (2.86\%).40.65\% of the children viewed TV, followed by smart-phones (39.56\%), touchscreen laptop (5.49\%). None of the children used Desktop or iPad. The prevalence of daily SV of two hours or more per day across all devices was $33.34 \%$, and the prevalence of TV, mobile device/ smart phone and touch screen laptop viewing was $28.57 \%, 29.52 \%$, and $4.76 \%$, respectively. 30 of $37(81.08 \%)$ having TV in the bedroom reported $>2$ hrs SV; $86.11 \%$ of those using smart phone and $100 \%$ of those using touch screen laptop had $>2 \mathrm{hrs}$ SV.

$5.71 \%$ of mothers were aware that "SV in children below the age of two should be minimised"; while almost $74.29 \%$ said "no" and 20\% said that they "did not know". 34.29\% of mothers set rules on time or programme of SV for children; while $28.57 \%$ set rules on both time and programme for other family members too. More i.e. 20 out of $36(55.56 \%)$ of those families with time restrictions had children with $>2$ hrs SV, while 15 out of 69 (21.74\%) in families without restrictions reported the same ( $p$ $<0.0001)$.

Increasing age (25\% of those $<6$ months, $30.30 \%$ in 6 12 months, $46.15 \%$ in $13-18$ months and $50 \%>18$ months) had a statistically significant $(p<0.0001)$ association with SV $>2$ hours. $58(25.86 \%)$ of male and 20 of $47(42.55 \%)$ of female children had $>2$ hrs SV $(p=0.18)$. Other variables like religion $(p=0.42)$, socio-economic status $(p=0.18)$, literacy status of father $(p=0.99)$, literacy status of mother $(p=0.17)$ and employment status of mother $(p=0.93)$ had no statistically significant difference in SV behaviour of the child. $28.07 \%$ of those from nuclear family and $39.58 \%$ of those from joint families had $>2$ hrs SV $(p=0.01)$.

Of the 91 families with digital devices, 37(40.65\%) of the children were able to operate the $\operatorname{TV}(81.08 \%$ with "great difficulty" and 18.92\% with "difficulty"); 36(39.56\%) smart-phones (83.33\% used it "easily", whereas $16.67 \%$ had "difficulty"); only five( $5.50 \%)$ children could operate the touch screen laptop(40\% "easily", 20\% "neither with difficulty nor easily" and rest $20 \%$ with "great difficulty"). (Figure 1) shows the parental beliefs on use of technology and screen viewing.

\section{Discussion}

In the study among 105 children less than two years of age, the prevalence of daily SV was $41.90 \%$ and most common screen devices used were TV and smart phones. SN Goh, et al. reported a higher prevalence of daily SV (53.5\%) and SV >2hours (16.3\%) (6). These differences can be due to the difference in accessibility, affordability and availability of electronic devices in the various study settings- the latter study being done in a developed country.

Only $5.71 \%$ of mothers were aware that "SV in children below the age of two should be minimized"; while SN Goh, et.al reported $12.7 \%$ of the parents being aware of the same (6). This difference in the awareness levels can be due to lack of proper health promotion interventions 
(effects of SDD and preventive recommendations) at the community level.

$34.29 \%$ of mothers set rules on time or programme of SV for children and $28.57 \%$ set rules on both time and programme for other family members too. Families with time restrictions had more children $>2 \mathrm{hrs}$ of SV, than families without restrictions. Similarly, the prevalence of SV was higher with increasing age and type of family. Higher SV in joint families may be due to neglect of the child due to large family size; another reason may be due to pampering of the child by other family members and parents being unable to impose any restrictions on the children. Parental television viewing time was seen to be associated with children's viewing time. SN Goh, et.al reported $75 \%$ of parents setting restrictions on both time and content. $(6,7)$ W Sanders, J Parent, R Forehand, found the SV habit of the children was also found to correlate very closely with parents'. Parents' limited knowledge about media use was seen to directly affect their ability to manage their children's media usage.(8)

The presence of TV $(81.08 \%)$ in the bedroom, access to smart-phones (86.11\%) and laptops (100\%) were associated with SV; similar results were reported by SN Goh, et.al.(9)

\section{Conclusion}

This study investigated SV pattern in detail in a very vulnerable age group. Child's age and type of family were significantly associated with higher prevalence of SV. Although TVs are regarded the most common form of screen device young children are exposed to, but in this study smart phones had similar usage rates; reiterating the fact that mobile devices have become widely available in the entire population and they now seem to be the second most important source of SV in young children. Parental knowledge and parental practices were also found to influence the SV and ST in children. The presence of TV in the bedroom and access to smart-phones and laptops were associated with more SV.

\section{Recommendation}

Certain important modifiable factors like parental knowledge on SV, parental SV practices can help in designing health promotion strategies. Screen dependency has not been much researched in children less than two years of age. This being a priority age group can be intervened and early childhood interventions aimed at reducing screen viewing given, so that they do not develop SDD in future. New set of recommendations on screen viewing and media use should be adopted and recommended, which will help families balance digital and real life from birth to adulthood. For this further research needs to be undertaken for advocating evidence based recommendations and develop early childhood interventions aimed at reducing screen viewing.

\section{Limitation of the study}

The limitation of the study being, the study was done in a single hospital setting, hence variations in the overall population in other settings may be there. Being a crosssectional study, it limits its ability to draw a causal relationship. Lastly, being a self-reported interview based report, there may be instances of reporting bias.

\section{Relevance of the study}

The current generation of children, grow-up immersed in digital media, which has both positive and negative effects on their health and development. Children being a nation's priority, new set of recommendations on screen viewing and media use should be adopted and recommended. The strengths of the study are it is first of its kind being done in the eastern part of India. This study focused on children under two years of age, who comprise a vulnerable group being exposed very early to the illeffects and consequences of exposure to blue light. It had a detailed outcome assessment of SV pattern and factors associated with it.

\section{Authors Contribution}

A.: Concept, design, definition of intellectual content, literature search, data acquisition and analysis, manuscript preparation, review and guarantor. IM: Concept, design, definition of intellectual content, literature search, data acquisition and analysis, manuscript preparation, editing, review and guarantor. $A B$ : design, definition of intellectual content, data acquisition and analysis, manuscript preparation, review and guarantor.

\section{Acknowledgement}

Approved ICMR STS 2019 study, submitted as a report to ICMR.

\section{References}

1. American College of Pediatricians • November 2016 • www.Best4Children.org The Impact of Media Use and Screen Time on Children, Adolescents, and Families from https://www.acpeds.org/wordpress/wp-content/uploads/11.9.16

2. Elicay, K. (2018, January 10). Screen Dependency Disorder Is Real, and It Damages Your Child's Brain. Accessed from https://www.smartparenting.com.ph/parenting/preschooler/scre en-dependency-is-now-considered-a-disorder-a00228-20180108

3. Sigmun, A. (2017, May). Screen Dependency Disorders: a new challenge for child neurology. Retrieved January 29, 2018, from https://www.researchgate.net/publication/317045692_Screen_D ependency_Disorders_a_new_challenge_for_child_neurology

4. Parent J, Sanders W, Forehand R. Youth screen time and behavioral health problems: the role of sleep duration and disturbances. J Dev BehavPediatr 2016; May

5. Vandewater EA, Rideout VJ, Wartella EA, Huang X, Lee JH, Shim MS. Digital childhood: electronic media and technology use among infants, toddlers, and preschoolers. Pediatrics. 2007 May;119(5):e1006-15. doi: 10.1542/peds.2006-1804. PubMed PMID: 17473074.[PubMed]

6. Goh SN, Teh LH, Tay WR, Anantharaman S, van Dam RM, Tan CS, Chua HL, Wong PG, Müller-Riemenschneider F. Sociodemographic, home environment and parental influences on total and devicespecific screen viewing in children aged 2 years and below: an 
INDIAN JOURNAL OF COMMUNITY HEALTH / VOL 32 / ISSUE NO 02 / APR - JUN 2020 observational study. BMJ Open. 2016 Jan 25;6(1):e009113. doi: 10.1136/bmjopen-2015-009113. PubMed PMID: 26810995; PubMed Central PMCID: PMC4735142.[PubMed]

7. Bleakley $A$, Jordan $A B$, Hennessy $M$. The relationship between parents' and children's television viewing. Pediatrics. 2013; 132 (2);
[Screen Dependency Disorders...] | Anjali et al Last accessed December 26th, 2018; from https://www.ncbi.nlm.nih.gov/pubmed/23858418

8. Sanders W, Parent J, Forehand R (2017, August). Parenting to Reduce Child Screen Time: A Feasibility Pilot Study

9. Tomopoulos Suzy DR., Dreyer BP DR., et al.(2011 May 16). Infant Media Exposure and Toddler Development

\section{Tables}

TABLE 1 SOCIO-DEMOGRAPHIC CHARACTERISTICS OF CHILDREN ( $=105)$

\begin{tabular}{|c|c|c|}
\hline Variables & $\mathrm{N}$ per group & Percent of total \\
\hline \multicolumn{3}{|l|}{ Age group (in months) } \\
\hline$<6$ & 33 & 31.43 \\
\hline $6-<12$ & 34 & 32.38 \\
\hline $13-<18$ & 23 & 21.9 \\
\hline $18-24$ & 15 & 14.29 \\
\hline \multicolumn{3}{|c|}{ Age in months (median, IQR) 9 months; Range 2 months to 24 months } \\
\hline \multicolumn{3}{|c|}{ Sex } \\
\hline Male & 58 & 55.24 \\
\hline Female & 47 & 44.76 \\
\hline \multicolumn{3}{|l|}{ Religion } \\
\hline Hindu & 95 & 90.48 \\
\hline Muslim & 5 & 4.76 \\
\hline Christian & 5 & 4.76 \\
\hline Others & 0 & 0 \\
\hline \multicolumn{3}{|c|}{ Socio-economic status(Modified Kuppuswami Scale) } \\
\hline Upper & 49 & 46.67 \\
\hline Upper middle & 27 & 25.71 \\
\hline Lower middle & 21 & 20 \\
\hline Upper lower & 8 & 7.62 \\
\hline Lower & 0 & 0 \\
\hline \multicolumn{3}{|l|}{ Literacy status of Father $(n=98)^{*}$} \\
\hline Illiterate & 0 & 0 \\
\hline Primary & 2 & 2.04 \\
\hline Secondary & 6 & 6.12 \\
\hline Higher secondary and above & 90 & 91.84 \\
\hline \multicolumn{3}{|l|}{ Literacy status of Mother } \\
\hline Illiterate & 1 & 0.95 \\
\hline Primary & 0 & 0 \\
\hline Secondary & 2 & 1.9 \\
\hline Higher secondary and above & 102 & 97.15 \\
\hline \multicolumn{3}{|l|}{ Type of family } \\
\hline Nuclear & 57 & 54.29 \\
\hline Joint & 48 & 45.71 \\
\hline \multicolumn{3}{|l|}{ Employment status of Mother } \\
\hline Employed & 19 & 18.1 \\
\hline Home-maker/house-wife & 86 & 81.9 \\
\hline
\end{tabular}

TABLE 2 TOTAL AND DEVICE-SPECIFIC SCREEN VIEWING ( $\mathrm{N}=105$ )

\begin{tabular}{|c|c|c|c|c|c|c|}
\hline & \multicolumn{2}{|c|}{ No screen viewing } & \multicolumn{2}{|c|}{ Upto 2 hrs of screen viewing } & \multicolumn{2}{|c|}{$\geq 2$ hrs of screen viewing } \\
\hline & $\mathrm{N}=61$ & Percent $=58.09$ & $\mathrm{~N}=9$ & Percent $=8.57$ & $\mathrm{~N}=35$ & Percent $=33.34$ \\
\hline Total screen time & NA* & NA & - & - & - & - \\
\hline Television( $(n=37)$ & NA & NA & 7 & 18.92 & 30 & 81.08 \\
\hline $\begin{array}{l}\text { Mobile phone/smart } \\
\text { phone( } n=36)\end{array}$ & NA & NA & 5 & 13.88 & 31 & 86.12 \\
\hline Laptop(n=0) & NA & NA & - & - & - & - \\
\hline
\end{tabular}




\begin{tabular}{|c|c|c|c|c|c|c|}
\hline $\begin{array}{l}\text { Touch } \\
\text { tablet }(n=5)\end{array}$ & NA & NA & 0 & 0 & 5 & 100 \\
\hline $\operatorname{iPad}(n=0)$ & NA & NA & - & - & - & - \\
\hline $\begin{array}{l}\text { Desktop } \\
\text { computer }(n=0)\end{array}$ & NA & NA & - & - & - & - \\
\hline Others $(n=0)$ & NA & NA & - & - & -- & \\
\hline
\end{tabular}

\section{Figures}

FIGURE 1 PARENTAL BELIEF ON USE OF TECHNOLOGY AND SCREEN VIEWING [N=105]

Many adolescents are more comfortable with internet socializing than they are with face-to-face interactions

Children of parents who consume too much screen time are more likely to develop screen dependency disorders

The younger a child is when she/he is exposed to screen time the more likely she/he is to develop screen dependency disorders with longterm effects

Children and adolescents whose technology gets taken away react aggressively, get bored easily and are commonly disinterred in anything else

Children who interact more with their devices than with humans may have less empathy for others

Children and adolescents may experience problems with neural development with long term effects

Children who spend too much time online may have an underdeveloped imagination

Children should have access to touch screen tablets at home and pre-school

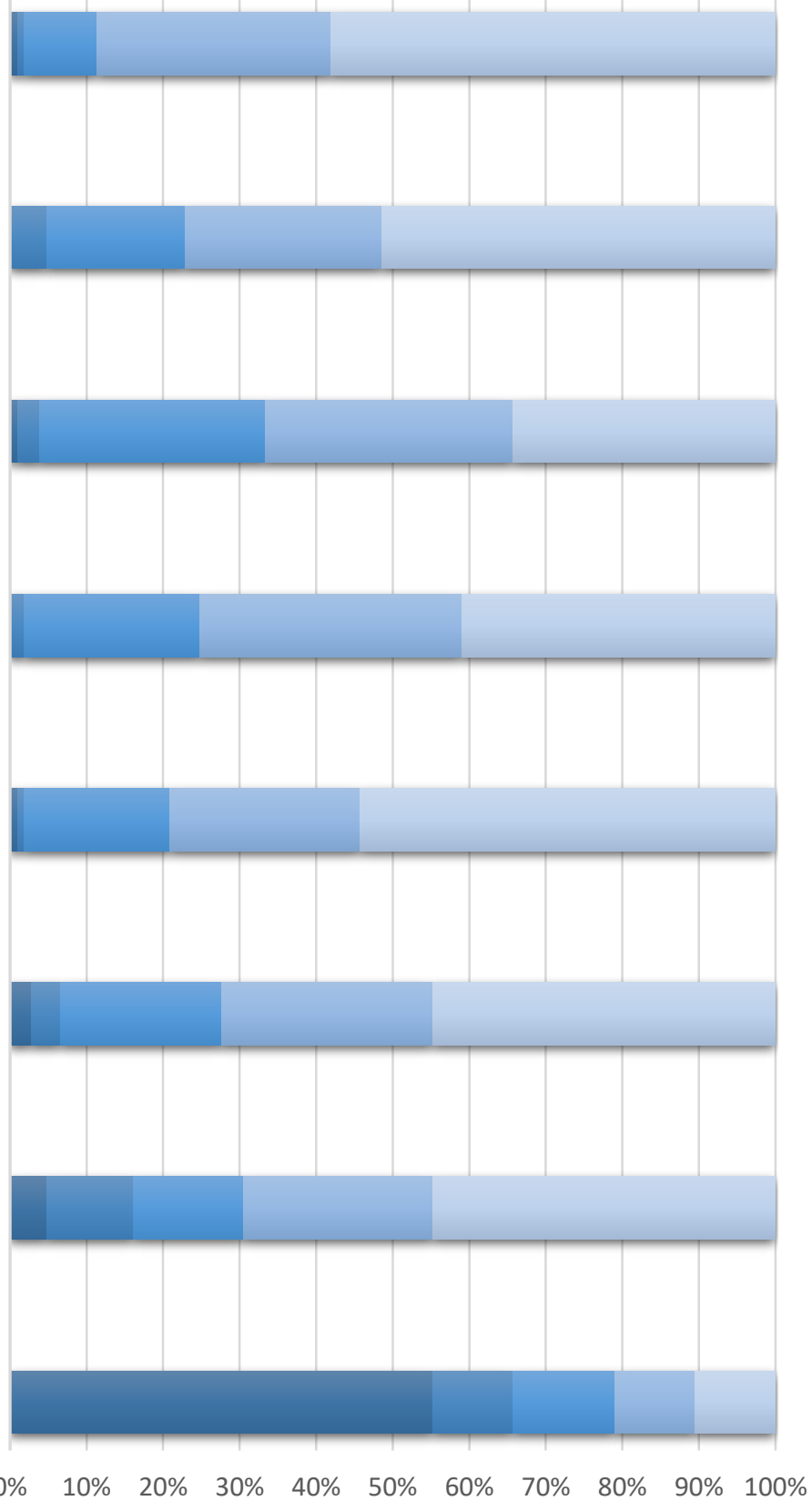

- Strongly disagree Disagree $\quad$ Neither agree nor disagree Agree $\quad$ Strongly agree 